\title{
Patologias dos sistemas hidráulicos e sanitários da Escola Dom Domingos Carrerot
}

Os Sistemas Hidráulicos e Sanitários são constituídos pelas instalações de água fria, água quente, esgotos e águas pluviais. Estes sistemas são uns do que entram em contato direto com o usuário, sendo que seu mau funcionamento é um indicativo de existência de patologias que resultam em queda do bem-estar físico e psicológico das pessoas. Assim este trabalho teve como objetivo avaliar as instalações hidráulicas e sanitárias da Escola Dom Domingos Carrerot, localizada no município de Porto Nacional/TO. A metodologia utilizada pautou-se em um estudo de caso realizado em uma escola pública estadual localizada no município de Porto Nacional. O estudo de caso baseou-se nos critérios de desempenho estabelecidos pela NBR 15575/2013. Os resultados demonstraram que os sistemas hidráulicos e sanitários da escola se encontram em bom estado de conservação, apresentando apenas algumas patologias. Ao final, concluiu-se que as patologias presentes na escola são: algumas torneiras que se encontravam quebras e por este motivo tinham vazamentos; reservatório de água da escola, que tem capacidade para armazenar 10.000 litros e apresentou estado de conservação insuficiente, devido possuir vários vazamentos pelo reservatório.

Palavras-chave: Sistemas Hidráulicos e Sanitários; Patologias; NBR 15575.

\section{Pathologies of the Domingos Carrerot School water and sanitary systems}

\begin{abstract}
The Plumbing and Sanitary Systems consist of cold water, hot water, sewage and rainwater installations. These systems are those that come into direct contact with the user, and their malfunction is indicative of the existence of pathologies that result in the fall of people's physical and psychological well-being. Thus, this work aimed to evaluate the plumbing and sanitary facilities of Dom Domingos Carrerot School, located in Porto Nacional/TO. The methodology used was based on a case study conducted in a state public school located in the city of Porto Nacional. The case study was based on the performance criteria established by NBR $15575 / 2013$. The results showed that the school's plumbing and sanitary systems are in good condition, with only a few pathologies. In the end it was concluded that the pathologies present in the school are: some taps that were broken and for this reason had leaks; The school's water reservoir, which has a capacity to store 10,000 liters and had an insufficient state of conservation, due to several leaks through the reservoir.
\end{abstract}

Keywords: Hydraulic and Sanitary Systems; Pathologies; NBR 15575.

Topic: Engenharia Civil

Reviewed anonymously in the process of blind peer.

Fernanda Pereira dos Santos

Instituto Tocantinense Presidente Antônio Carlos, Brasil

http://lattes.cnpq.br/0786456263928132

fernandaalmofadinhas@hotmail.com

Eduardo Gouveia Santiago Lage

Instituto Tocantinense Presidente Antônio Carlos, Brasil

http://lattes.cnpq.br/4344949197847151

http://orcid.org/0000-0003-0011-2451

fernandaalmofadinhas@hotmail.com
Received: 14/12/2019

Approved: 10/02/2019
Referencing this:

SANTOS, F. P.; LAGE, E. G. S.. Patologias dos sistemas hidráulicos e sanitários da Escola Dom Domingos Carrerot. Engineering Sciences, v.8, n.1, p.17-26, 2020. DOI: http://doi.org/10.6008/CBPC2318$\underline{3055.2020 .001 .0003}$ 


\section{INTRODUÇÃO}

As instalações prediais hidráulico-sanitárias têm como finalidade fazer a distribuição de água, em quantidade suficiente e sob pressão adequada a todas as peças de utilização e aparelhos sanitários da edificação, promover a coleta e o abastamento adequados das águas pluviais e das águas servidas, impedir o retorno de águas poluídas nas canalizações de alimentação dos aparelhos bem como a entrada de gases de esgoto, roedores ou insetos nos edifícios, criando, desta forma, condições favoráveis ao conforto e segurança dos usuários (CARVALHO JUNIOR, 2014).

A complexidade funcional intrínseca e a inter-relação dinâmica dos diversos subsistemas; a enorme variedade de materiais; componentes e equipamentos, como tubos, conexões, registros, válvulas, acessórios, reservatórios, bombas, tanques, equipamentos de controle e medição, dentre outros, são características inerentes aos sistemas prediais hidráulicos e sanitários, também conhecido como SPHS (MACEDO, 2015).

As particularidades do sistema predial hidráulico e sanitário é algo que pode desencadear diversas manifestações patológicas nas edificações, sendo que estas vão desde falhas mais comuns e frequentes que ocorrem em certos equipamentos até um emaranhado de variações de grandezas hidráulicas, térmicas e pneumáticas que estão associadas à utilização dos aparelhos sanitários (TEIXEIRA et al., 2011).

Existe, ainda, o problema da ocupação ou utilização que a edificação está sujeita, uma vez que o tempo de utilização provoca um processo natural e progressivo de obsolescência nos sistemas prediais hidráulicos e sanitários, sendo os fatores os mais variados, como manutenção ineficiente ou irregular, desgastes, envelhecimento natural dos materiais utilizados, falha nos componentes e condições de exposição inadequadas. O mau desempenho dos sistemas prediais hidráulicos e sanitários acabam gerando sérios problemas ao bem-estar físico e psicológico dos usuários (TOZEVICH et al., 2015).

Araújo (2014) afirma que as instalações prediais hidráulicas e sanitárias devem possuir condições de uso durante toda a vida útil da edificação, sendo que as instalações hidráulicas e sanitárias devem funcionar adequadamente, pois são responsáveis por disponibilizarem vários insumos, como é o caso da água aos usuários. Desta maneira, as qualidades destas instalações possuem implicações no desempenho que atenda às necessidades das pessoas, bem como a racionalização em relação às perdas, desperdícios e utilização de insumos adequados.

As consequências das patologias que surgem em uma edificação ao longo de sua vida útil, sujeitam os usuários a vivenciar transtornos que estão relacionados aos sistemas hidráulicos e sanitários. Ressalta-se que, em menor escala, os próprios usuários são responsáveis pelo aparecimento dessas patologias, seja devido a desinformação, por deficiência ou inexistência de manutenção, ou pela utilização inadequada dos aparelhos sanitários, devido os mesmos serem o maior ponto de contato destes usuários (TEIXEIRA et al., 2011).

Desta maneira, uma problemática norteou a presente pesquisa, sendo esta: quais são as patologias mais comuns dos sistemas hidráulicos e sanitários da escola Dom Domingos Carrerot? Quais são as causas destas patologias? 
Como futura profissional da área de engenharia civil, percebe-se que as patologias dos sistemas prediais hidráulicos e sanitários são algo que merecem atenção, conhecimento e ação, uma vez que estas patologias acabam provocando uma grande insatisfação nos usuários. O objetivo da pesquisa foi o de avaliar as instalações hidráulicas e sanitárias da Escola Dom Domingos Carrerot, localizada no município de Porto Nacional/TO.

\section{REVISÃO TEÓRICA}

\section{Instalações Hidrossanitárias}

Os sistemas prediais hidráulicos e sanitários, ou SPHS, possuem características inerentes ao próprio sistema, sendo estas a complexidade funcional intrínseca e a inter-relação dinâmica dos diversos subsistemas, além da grande variedade de materiais, componentes e equipamentos que constituem os SPHS, como por exemplo os tubos, conexões, registros, válvulas, acessórios, reservatórios, bombas, tanques, equipamentos de controle e medição, dentre outros (ILHA, 2009).

Estas peculiaridades podem provocar uma grande diversidade de manifestações patológicas nas edificações, indo desde falhas frequentes em alguns equipamentos até intricadas variações associadas à utilização dos aparelhos sanitários (TEIXEIRA et al., 2011). A partir do momento que se inicia o processo de ocupação ou utilização de uma edificação, a mesma fica sujeita ao processo natural progressivo de obsolescência nos sistemas prediais hidráulicos e sanitários originais, provocado por múltiplos fatores. Entre estes fatores, cita-se a manutenção deficiente ou irregular, falha nos componentes, processos naturais de desgaste ou envelhecimento natural dos materiais utilizados e condições de exposição inadequadas.

\section{Sistemas Hidráulicos}

Os sistemas hidráulicos estão definidos, legalmente, na NBR 5626, sendo que a mesma descreve que uma instalação predial de água fria é um sistema composto por tubos, peças de ventilação, reservatórios, equipamentos, dentre outros componentes, sendo que este sistema possui como propósito conduzir a água fria da fonte fornecedora até os pontos de utilização (ABNT, 1998).

Existem requisitos que são primordiais aos sistemas hidráulicos, sendo estes: preservação da potabilidade da água, garantia do fornecimento da água de maneira continua e em quantidade adequada com velocidade e pressão de acordo com os aparelhos de destino, manutenção fácil e econômica, bem como, deve proporcionar conforto aos usuários (CARVALHO JUNIOR, 2014).

O abastecimento contínuo de água aos usuários em quantidade suficiente, reduzindo os problemas decorrentes da interrupção do funcionamento do sistema público, limitação de certos valores de pressões e velocidades são alguns objetivos de um projeto de instalação predial de água fria e quente. Estes objetivos estão previstos na NBR 5626 e busca assegurar o bom funcionamento da instalação, evitando, assim, consequentes vazamentos e ruídos nas canalizações e aparelhos.

Em relação aos vazamentos, os mesmos ocorrem por diversos fatores, entre eles destaca-se, 
principalmente, o desgaste natural de sistemas hidráulicos antigos e instalações hidráulicas malfeitas. Existem vazamentos de fácil detecção, percebidos através de testes rápidos ou da simples inspeção nos produtos, e outros mais difíceis de serem detectados no qual é necessário o auxílio do aparelho de geologia para identifica-los. Os pontos mais críticos das tubulações estão nas conexões/junções. É importante zelar pela qualidade da água por meio de técnicas de distribuição e armazenamento coerentes e adequadas, assegurando higiene, saúde e conforto ao usuário (REALI et al., 2002).

\section{Patologias dos sistemas hidráulicos}

As patologias dos sistemas hidráulicos são provenientes de problemas nas instalações hidráulicas prediais e isto é decorrente do fato de que não se dá a atenção que de fato precisa para o projeto hidráulico. São falhas decorrentes da qualidade dos materiais utilizados; na execução, podendo ser pela falha na mão de obra ou pela falha na fiscalização ou omissão do construtor (CARVALHO JUNIOR, 2015).

Geralmente, as falhas de projeto, são provenientes da falta de entrosamento e comunicação entre os profissionais contratados para a elaboração dos projetos complementares. Quando isso ocorre, é possível que aconteça falhas no processo de produção do projeto provenientes da incompatibilização, gerando improvisações visando solucionar os problemas que surgiram. Os motivos mais comuns de problemas por causa das falhas de projeto podem ocorrer devido falhas de concepção sistêmica; erros de dimensionamento; incorreções das especificações de materiais e serviços; insuficiência ou inexistência de detalhes construtivos (ILHA, 2009).

São cada vez maiores a quantidade e a complexidade dos equipamentos utilizados nas instalações de água e esgoto e isto está relacionado com os problemas sistêmicos, uma vez que está complexidade dificulta a mão de obra especializada. Atualmente utiliza-se equipamentos como medidores individualizados de água, estação de tratamento de esgoto, aparelhos de aquecimento solar, equipamentos de reuso de água pluvial, dentre outros.

Os projetistas enfrentam desafios como a compatibilização dos equipamentos em um espaço físico cada vez menor e limitado. Para facilitar a manutenção e racionalizar as instalações, é necessário fazer essa compatibilização, uma vez que a sua ausência pode provocar diversos problemas, como: falta de espaço para a instalação de hidrômetros de medição individualizada, ruídos causados por, entre outros fatores, bombas centrífugas instaladas indevidamente em subsolos de prédios sem tratamento acústico e falta de espaço na casa de bombas (CARVALHO JUNIOR, 2015).

\section{Sistemas Sanitários}

As instalações prediais de esgotos sanitários destinam-se a coletar, conduzir e afastar da edificação todos os despejos provenientes do uso adequado dos aparelhos sanitários, dando-lhes um rumo apropriado, normalmente indicado pelo poder público competente. A condução dos esgotos sanitários à rede pública ou ao sistema receptor será feita, sempre que possível, por gravidade (CARVALHO JUNIOR, 2014).

Quando houver rede pública, em condições de atendimento, as instalações de esgoto das edificações 
deverão ligar-se obrigatoriamente a ela, respeitando a exigência das concessionárias. Resíduos líquidos, sólidos ou em qualquer estado de agregação da matéria, provenientes de edificações, somente podem ser despejados em água interiores ou costeiras, superficiais ou subterrâneas, após receberem tratamento que proporcionem a redução dos índices poluidores aos valores compatíveis com os corpos receptores, respeitada a legislação de proteção do meio ambiente (CREDER, 2018).

As condições técnicas para projeto e execução das instalações prediais de esgoto sanitário, em atendimento às exigências mínimas quanto à higiene, economia e conforto dos usuários, são fixadas pela NBR 8160 - sistemas prediais de esgoto sanitário - projeto e execução. De acordo com a norma, o sistema de esgoto sanitário deve ser projetado de modo a: Evitar a contaminação da água, de forma a garantir sua qualidade de consumo, tanto no interior dos sistemas de suprimento e de equipamentos sanitários, como nos ambientes receptores; Permitir rápido escoamento de água utilizada e dos despejos introduzidos, evitando a ocorrência de vazamentos e a formação de depósitos no interior das tubulações; Impedir que os gases provenientes do interior do sistema predial de esgoto sanitário atinjam áreas de utilização; Impossibilitar o acesso de corpos estranhos ao interior do sistema; Permitir que seus componentes sejam facilmente inspecionáveis; Impossibilitar o acesso de esgoto ao subsistema de ventilação; Permitir a fixação dos aparelhos sanitários somente por dispositivos que facilitem sua remoção para eventuais manutenções; Não interligar o sistema de esgoto com outros sistemas.

As principais partes constituintes de uma instalação predial de esgoto sanitário estão representadas de forma esquemática nas figuras 1 e 2. Os principais componentes de um sistema predial de esgoto são: aparelhos sanitários, desconectores ou sifões, ralos, caixas sifonadas, ramal de descarga, ramal de esgoto, tubo de queda, coluna de ventilação, subcoletor, dispositivos de inspeção (caixa de inspeção e caixa de gordura), coletor predial e válvula de retenção (MACINTYRE, 2017).

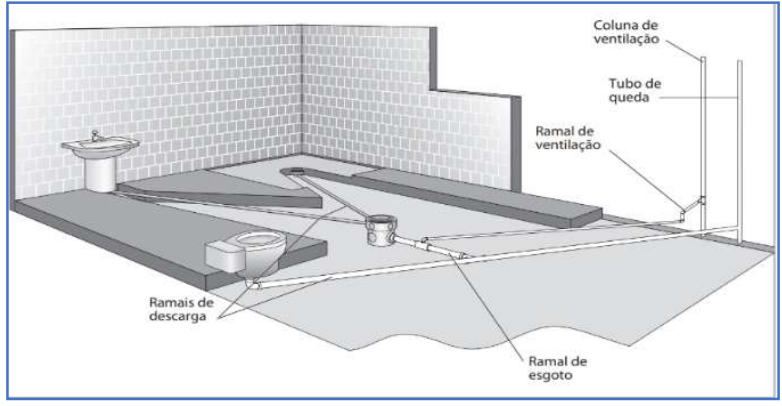

Figura 1: Partes constituintes de uma instalação predial de esgoto. Fonte: Carvalho Junior (2014).

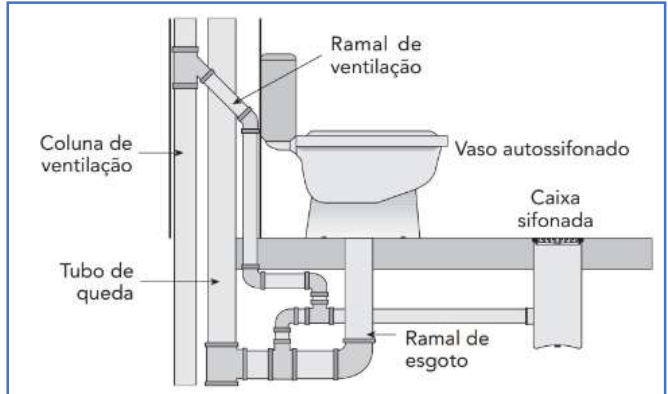

Figura 2: Partes constituintes de uma instalação de esgoto em corte esquemático. Fonte: Carvalho Junior (2014).

De acordo com a NBR 8160, os materiais a serem empregados nos sistemas prediais de esgoto sanitário devem ser especificados em função do tipo de esgoto a ser conduzido, de sua temperatura, dos efeitos químicos e físicos e dos esforços ou solicitações mecânicas a que possam ser submetidas as instalações. Os materiais usualmente empregados nas tubulações e conexões de esgoto são o PVC linha sanitária (série normal e reforçada), o ferro fundido e a manilha cerâmica. Não podem ser utilizados nos sistemas de esgoto sanitário, materiais ou componentes não constantes da normalização brasileira (CREDER, 
2018).

As prumadas de esgoto e ventilação, assim como as de água fria e quente, devem ser definidas pelo profissional de instalações, para adequar-se às barreiras impostas pelo projeto de estrutura e integrar-se de forma harmônica ao projeto arquitetônico. As canalizações embutidas não devem estar solidárias às peças estruturais do edifício. Deve-se condicionar a escolha dos pontos de descida dos tubos de queda para o mais próximo possível de pilares, ou da projeção dos pilares e paredes do térreo (MACINTYRE, 2017).

Com relação às conexões, deve-se utilizá-las de forma racional, evitando, sempre que possível, as mudanças bruscas de direção no traçado das redes. É preferível a utilização de caixas de passagem (inspeção) nas mudanças de 90, em trechos horizontais (CREDER, 2018). Para a escolha do posicionamento da caixa sifonada com grelha, devem-se levar em consideração aspectos técnicos e estéticos, já que o piso deverá apresentar declividade favorável ao escoamento das águas para a caixa. De forma geral, quanto mais próxima a caixa sifonada (ralo) estiver da ligação com o ramal de esgoto, mais simples será a instalação da ventilação (CARVALHO JUNIOR, 2014).

\section{Patologias dos sistemas sanitários}

Os sistemas sanitários podem apresentar diversas patologias e por consequência, podem, ainda, contaminar a água potável do ambiente externo, interno e provocar mau cheiro. Dentre as diversas patologias que podem ocorrer em um sistema sanitário, as mais comuns são: mau cheiro, retorno de espuma, vazamentos em tubulações, ruptura do fecho hídrico, infiltrações e entupimento nas canalizações (CARVALHO JUNIOR, 2014).

O mau cheiro pode ser provocado por: Ausência ou vedação inadequada na saída dos vasos sanitários; Ausência ou sistema de ventilação inadequada. Por este motivo é importante que se verifique corretamente se o fecho hídrico é menor que 50mm; Confirmar existência de juntas elásticas ou de cera na saída dos vasos sanitários; verificar o nível de líquido no interior das caixas sifonadas ao acionar descarga em vaso sanitário que estiver próximo; Observar se o plug do sifão das caixas sifonadas encontra-se posicionado corretamente; Verificar se a extremidade superior da tubulação de ventilação encontra-se livre de obstáculos à passagem do ar (VIRGíLIO, 2017).

Quando não se faz adequadamente as instalações dos sifões, além do mau cheiro, existe também a possibilidade de entupimento da tubulação que está embutida na parede, o que acaba gerando um maior trabalho nas ações de manutenção e desobstrução. Em prédios que possuem pavimentos sobrepostos, é importante que haja um tubo de queda exclusivo para os ramais de descarga de pias de cozinhas, que irão conduzir os efluentes para uma caixa de gordura coletiva situada no térreo da edificação. Deve-se realizar a limpeza semanal das caixas de gordura para se garantir o funcionamento adequado do sistema (CARVALHO JUNIOR, 2014).

Quanto ao retorna de espuma, a NBR 15575/2013 enfatiza a importância do projeto e execução com corretos sistemas de ventilação e selos hídricos para as instalações de esgoto, além de existir uma correta disposição das caixas de gordura e inspeção, sem que exista o risco de retorno da espuma (ABNT, 2013). 
Quando ocorre retorno de espuma por meio das caixas sifonadas e grelhas de ralos é porque, provavelmente, a ligação de ramis de esgoto foi realizada em regiões de sobre pressão, e por isso deve-se verificar se a ligação dos ramais de esgoto da máquina de lavar roupas com as colunas estão na área de sobre pressão da maneira que a NBR 8610/1999 conceitua (CARVALHO JUNIOR, 2014).

Os entupimentos de tubulações são provocados, na grande maioria das vezes, pela falta de informações e de conscientização dos usuários e moradores, inclusive nos subcoletores que normalmente se localizam nas áreas mais comuns dos edifícios. O acúmulo de materiais sólidos (de natureza inorgânica) depositados de uma maneira contínua, junto com a falta de declividade na canalização podem causas a total ou parcial obstrução da tubulação. O triturador de alimentos localizado de baixo da pia tem um papel importante para a redução de riscos de entupimento, tanto em subcoletores e coletores prediais, como em ramais de descarga e esgoto (VIRGílIO, 2017).

\section{METODOLOGIA}

Trata-se de um estudo de caso realizado em uma escola pública estadual localizada no município de Porto Nacional. Esse local foi escolhido devido está escola está localizada em um setor estratégico do município (setor aeroporto), e ser de fácil acesso. A metodologia empregada no desenvolvimento da pesquisa seguiu os preceitos de uma avaliação pós-ocupação (APO) e teve como objetivos de estudos os sistemas prediais hidráulicos e sanitários de água fria e esgoto.

O estudo de caso baseou-se nos critérios de desempenho estabelecidos pela NBR 15575/2013 Desempenho de edifícios habitacionais de até cinco pavimentos, apesar da mesma não estar voltada especificadamente para o caso, foi utilizada por conter definições que são aplicáveis às instalações hidrossanitárias encontradas e pelo fato de não haver outra norma vigente para este tipo de edificação.

O período de realizado da pesquisa compreendeu os meses de agosto a setembro de 2019. Foram elaboradas planilhas para o levantamento em campo que buscaram abranger os critérios de desempenho e as exigências constantes nas normas regulamentadoras existentes. Essas planilhas constituíram o levantamento quantitativo e qualitativo dos aparelhos e equipamentos hidrossanitários, paralelamente ao levantamento quantitativo das manifestações patológicas identificadas. Também foram categorizados os materiais dos aparelhos e equipamentos e condições de uso. Os modelos das planilhas seguem no Anexo desta pesquisa.

Ressalta-se que o levantamento em campo consistiu na inspeção visual e na realização de alguns testes para a avaliação dos sistemas prediais e dos aparelhos e equipamentos sanitários, que aconteceu por meio do preenchimento das planilhas e da utilização do Geofone, que é um aparelho utilizado para localizar vazamentos não visíveis pelo método da acústica. Com este aparelho, foi possível fazer a busca por vazamentos ocultos. A verificação do estado de conservação e a condição de operação da maioria dos pontos de consumo e respectivos aparelhos e equipamentos sanitários foi realizada visualmente, sendo as manifestações patológicas, registradas nas planilhas de levantamento e em material fotográfico. 


\section{RESULTADOS}

O abastecimento de água fria de todo o campo da Escola Estadual Dom Domingos Carrerot é feito pela rede pública de água BRK Ambiental. É uma escola que possui dois hidrômetros, sendo que um hidrômetro alimenta toda a escola no que diz respeito a torneiras, banheiros, caixas d'água, vasos e o outro hidrômetro alimenta somente as torneiras do jardim que são utilizadas para molhar as plantas e lavar o pátio externo. É uma escola que possui apenas um reservatório de água, ou seja, uma caixa d’água de polietileno com capacidade de armazenagem para 10.000 litros.

Quanto ao sistema de coleta e disposição de esgoto, a escola possui disposição adequada, uma vez que todo o esgoto é lançado na rede coleta e é levado para a estação de tratamento de esgoto (ETE) da BRK Ambiental, que realiza uma série de procedimentos para tratá-lo e deixá-lo livre de resíduos sólidos e microorganismos. Sendo assim, o efluente, pode retornar para a natureza despoluído.

Quanto ao sistema predial de água pluvial, o mesmo é formado por duas águas, sendo que a água proveniente da chuva é escoada pelas calhas e é drenada para o solo, ou seja, escoam livremente para as áreas permeáveis do terreno. Os rufos do prédio se encontravam em condições aceitável de fixamento e vedação. Para a observação de todo o conjunto hidráulico e sanitário da escola, foi utilizada uma planilha para o levantamento das informações a respeito das manifestações patológicas, além de ter sido utilizado o Geofone para localizar possíveis vazamentos não visíveis.

Nas análises efetuadas, foram consideradas as seguintes definições: Estado de conservação referente a aparência do aparelho/equipamento sanitário, como por exemplo: se estava quebrado, enferrujado, mal encaixado. Condições de operação correspondente ao funcionamento, podendo o aparelho/equipamento sanitário apresentar vazamentos, não fechar, estar em desuso, entupido, dentre outros. Ressalta-se que estes parâmetros foram analisados conforme os critérios da NBR 15575/2013 - Desempenho de edifícios habitacionais de até cinco pavimentos. A distribuição da análise dos sistemas hidráulicos e sanitários da escola Dom Domingos Carrerot está demonstrada na tabela a seguir.

Tabela 1: Análise dos sistemas hidráulicos e sanitários da escola Dom Domingos Carrerot de Porto Nacional/TO, 2019.

\begin{tabular}{|l|l|l|}
\hline \multicolumn{1}{|c|}{ ITEM } & \multicolumn{1}{c|}{$\begin{array}{c}\text { QTD } \\
\text { ENCONTRADA }\end{array}$} & \multicolumn{1}{c|}{ DESCRIÇÃo DA SIUTAÇÃo } \\
\hline Bacia Sanitária & 09 & $\begin{array}{l}\text { Todas as bacias sanitárias encontradas possuem válvulas de descarga e todas são tipo adulto e } \\
\text { estavam funcionando em bom estado de conservação. }\end{array}$ \\
\hline Chuveiros & 05 & $\begin{array}{l}\text { Todos estavam em situação satisfatória, já que apresentavam fixação e condição de operação } \\
\text { adequada. }\end{array}$ \\
\hline $\begin{array}{l}\text { Lavatório } \\
\text { (Torneira/Pia/Sifão) }\end{array}$ & 08 & $\begin{array}{l}\text { Os lavatórios eram constituídos por torneira, pia e sifão e todos encontravam-se em situação } \\
\text { adequada de uso, exceto algumas torneiras que se encontravam quebras e por este motivo } \\
\text { tinham vazamentos. }\end{array}$ \\
\hline Ralos & 06 & Todos os ralos estavam dentro do padrão de qualidade e desempenho. \\
\hline Bebedouro & 02 & Os bebedouros encontram-se em situação satisfatória. \\
\hline Tubos e conexões & - & Não foram encontrados tubos e conexões em situação insatisfatória. \\
\hline Reservatório de água & 01 & $\begin{array}{l}\text { Possui um reservatório de água de 10.000 litros que apresenta estado de conservação } \\
\text { insuficiente. Possui vários vazamentos pelo reservatório. }\end{array}$ \\
\hline
\end{tabular}

Esta escola atende 310 (trezentos e dez) alunos e 38 (trinta e oito) funcionários, com um consumo médio de água de $794 \mathrm{~m}^{3}$ de água em 32 dias, conforme a última leitura analisada que foi referente ao mês de agosto de 2019. 


\section{DISCUSSÃO}

Percebeu-se durante a análise das patologias dos sistemas hidráulicos e sanitários da escola que a mesma praticamente não apresenta manifestações patológicas, sendo que as que foram apresentadas estão nas torneiras, que estavam com vazamentos. Estes problemas são devido a uma ausência de manutenção destes itens, ou simplesmente a não adequação em relação ao desempenho pelo que é exigido pela Norma Brasileira de Desempenho de Edifícios Habitacionais de até 5 pavimentos NBR 15575/2013.

Essa norma está em vigor desde o ano de 2013 aborda o desempenho de edificações habitacionais. Esta norma procura atender às exigências dos usuários. Com isso fixa os níveis de desempenho mínimos para os principais sistemas da edificação como, por exemplo, as vedações, estrutura, instalações hidrossanitárias e elétricas, pisos, fachada e cobertura. Explora conceitos como a durabilidade dos sistemas, o período entre as manutenções da edificação, o conforto tátil e antropodinâmico dos usuários (SOUZA et al., 2017).

Destaca-se, ainda, que é importante atentar-se para a substituição das torneiras que apresentaram vazamentos, uma vez que essa ação contribuirá para a redução no consumo de água. Em uma pesquisa realizada por Soares (2012) na Universidade Federal de Campina Grande, o autor constatou que a troca das torneiras convencionais por hidromecânica e por sensor de presença, resultaram em uma redução no consumo de água de $20 \%$ e $40 \%$ e 2,14 anos e 3,23 anos de retorno do investimento, respectivamente.

Percebeu-se que ao reservatório de água da escola possui capacidade para armazenar 10.000 litros, porém o mesmo apresentou situação inadequada de uso por conter vazamentos provenientes de furos, o que pode está aumentando o consumo médio de água da escola, que é de $794 \mathrm{~m}^{3}$ de água/mês. Ressalta-se que esse consumo é para atender a escola no que diz respeito a alunos e servidores. Para atender a demanda externa da escola, como por exemplo para molhar as plantas, a escola possui um hidrômetro separado, sendo que o consumo do mesmo é de $106 \mathrm{M}^{3} / \mathrm{mês}$.

Guimarães et al. (2016) aplicaram uma metodologia baseada em um Programa de Uso Racional da Água - PURA na Escola Estadual de Primeiro e Segundo Grau Fernão Dias Paes, São Paulo. A detecção e correção dos vazamentos proporcionou uma redução do consumo mensal de $94 \%$ e a substituição dos componentes convencionais por economizadores, uma redução de $9 \%$. Observa-se assim que o impacto de redução total no sistema após as ações de intervenção foi de $95 \%$.

Na busca de um valor que servisse como parâmetro de análise do indicador de consumo de água em escolas, Oliveira (2013) realizou comparações com valores encontrados em diversos trabalhos para escolas públicas de ensino fundamental e médio com o valor determinado pelo Decreto Estadual/SP no 45.805/2001. Foi encontrado valor admissível na classe de 10,01 litros/agente consumidor/dia. O autor acrescenta, ainda, que nas escolas de ensino fundamental e médio, consumos superiores a 10,01 litro (agente consumidor/dia) sejam devidos, basicamente, ao desperdício pelo uso inadequado dos equipamentos hidrossanitários, pelos vazamentos visíveis ou não visíveis e pelos equipamentos hidrossanitários que consomem muita água. 


\section{CONCLUSÕES}

Os Sistemas Hidráulicos e Sanitários possuem algumas características como a complexidade funcional intrínseca e a inter-relação dinâmica dos seus diversos subsistemas, além da grande variedade de materiais, componentes e equipamentos constituintes, como por exemplo, os tubos, as conexões, os registros, as válvulas, os acessórios, os reservatórios, as bombas, os tanques, dentre outros. Todos estes componentes podem dar origem a uma grande diversidade de manifestações patológicas nas edificações. Assim este trabalho teve como objetivo avaliar as instalações hidráulicas e sanitárias da Escola Dom Domingos Carrerot, localizada no município de Porto Nacional/TO.

A avaliação das instalações hidráulicas e sanitárias da escola foram realizadas conforme os critérios da NBR 15575/2013 - Desempenho de edifícios habitacionais de até cinco pavimentos, e logo após a avaliação constatou-se que os componentes dos sistemas hidráulicos e sanitários estavam em perfeito estado de conservação e não apresentaram nenhuma patologia, exceto algumas torneiras que se encontravam quebras e por este motivo tinham vazamentos. Oura constatação está relacionada ao reservatório de água da escola, que tem capacidade para armazenar 10.000 litros e apresentou estado de conservação insuficiente, devido possuir vários vazamentos pelo reservatório.

\section{REFERÊNCIAS}

ABNT. Associação Brasileira de Normas Técnicas. NBR 5626: Instalação Predial de Água Fria. Rio de Janeiro: ABNT, 1998.

ABNT. Associação Brasileira de Normas Técnicas. NBR 1557: Edificações habitacionais: Desempenho. Parte 2: requisitos para os sistemas estruturais. Rio de Janeiro: ABNT, 2013.

ARAÚJO, L. S. M.. Avaliação durante operações dos sistemas prediais hidráulicos e sanitários em edifícios escolares. Dissertação (Mestrado em Engenharia Civil, Arquitetura e Urbanismo) - Universidade Estadual de Campinas, Campinas, 2014.

CARVALHO JUNIOR, R.. Instalações prediais hidráulicosanitárias: princípios básicos para a elaboração de projetos. São Paulo: Blucher, 2014

CREDER, H.. Instalações hidráulicas e sanitárias. 6 ed. Rio de Janeiro: LTC, 2018

GUIMARÃES, F. B.; ARAÚJO, S. S.. Diagnóstico do uso da água em uma escola de tempo integral e considerações sobre o uso racional. Monografia (Graduação em Engenharia Ambiental e Sanitária) - Universidade Federal de Goiás, Goiânia, 2016.

ILHA, M. S. O.. A investigação patológica na melhoria dos sistemas prediais hidráulico-sanitários. Hydro e Aranda, São Paulo, v.30, n.30, p.60-65, 2009.

MACEDO, N. P.. Estudo de patologias em instalações prediais de abastecimento de água e de drenagem de águas residuais. Dissertação (Mestrado em Engenharia) Universidade do Porto, Porto, 2015.

MACINTYRE, A. J.. Instalações hidráulicas: prediais e industriais. 4 ed. Rio de Janeiro: LTC, 2017.
OLIVEIRA, F. R. G.. Consumo de água e percepção dos usuários para o uso racional de água em escolas estaduais de Minas Gerais. Dissertação (Mestrado em Engenharia Civil) - Universidade Federal de Uberlândia, Uberlândia, 2013.

REALI, M. A. P.; MORUZZI, R. B.; PICANÇO, A. P.; CARVALHO, K. Q.. Instalações prediais de água fria. São Paulo: Universidade de São Paulo, 2002.

SOARES, A. L. F.. Gerenciamento da demanda de água em ambiente de uso público: o caso da universidade federal de Campina Grande. Dissertação (Mestrado em Engenharia Civil e Ambiental) - Universidade Federal de Campina Grande, Campina Grande, 2012.

SOUZA, G.; MELO, S. P.. Estudo das manifestações patológicas em instalações prediais de água fria e de esgoto sanitário de edificação residencial privativa multifamiliar. Monografia (Graduação em Engenharia Civil) Universidade do Sul de Santa Catarina, Florianópolis, 2017.

TEIXEIRA, P.; REIS, R. P. A.; GNIPPER, S. F.; MONTEIRO, J. V. F.. Estudo de patologias nos sistemas prediais hidráulicos e sanitários do prédio do ciclo básico II da Unicamp. Revista Eletrônica de Engenharia Civil, n.2, p.34-50, 2011.

TOZEVICH, P. L.; VOGT, W. M.; DARONCO, G. C.; MOURA, D. D.. Patologias em sistemas prediais de água fria. Unjuí: Salão do Conhecimento Luz-Ciência-Vida, 2015.

VIRGILIO, P. S. V.. Estudo de manifestações patológicas pós ocupação de empreendimento para elaboração de um manual de execução. Monografia (Graduação) Universidade Federal de Santa Catarina, Florianópolis, 2017

A CBPC - Companhia Brasileira de Produção Científica (CNPJ: 11.221.422/0001-03) detém os direitos materiais desta publicação. Os direitos referem-se à publicação do trabalho em qualquer parte do mundo, incluindo os direitos às renovações, expansões e disseminações da contribuição, bem como outros direitos subsidiários. Todos os trabalhos publicados eletronicamente poderão posteriormente ser publicados em coletâneas impressas sob coordenação da Sustenere Publishing, da Companhia Brasileira de Produção Científica e seus parceiros autorizados. Os (as) autores (as) preservam os direitos autorais, mas não têm permissão para a publicação da contribuição em outro meio, impresso ou digital, em português ou em tradução. 